Article

\title{
Advancing Medical Tourism in the United Arab Emirates: Toward a Sustainable Health Care System
}

\author{
Hallow Al-Talabani, Hasan Kilic, Ali Ozturen *(1) and Suhad Othman Qasim \\ Faculty of Tourism, Eastern Mediterranean University, Gazimagusa, North Cyprus, PO Box 99628, via Mersin 10, \\ Turkey; 15600167@students.emu.edu.tr (H.A.-T.); hasan.kilic@emu.edu.tr (H.K.); \\ sihad.qasim@emu.edu.tr (S.O.Q.) \\ * Correspondence: ali.ozturen@emu.edu.tr
}

Received: 27 November 2018; Accepted: 27 December 2018; Published: 4 January 2019

check for updates

\begin{abstract}
Medical tourism provides an essential advantage for destinations. On the other hand, the knowledge of developing competitive medical tourism destinations is still limited. This study models a conceptual framework on novel ways of sustaining the United Arab Emirate (UAE) Vision 2020 with reference to the existing models on behavior. In the current study, the Theory of Planned Behavior (TPB), which is health-related, along with the Finance, System and connection (FSC) model, is employed. Using an empirically based methodology, the data for the investigation is collected with the aid of a questionnaire. As such, the study employs finance, system, and connections variables which are commonly adopted in testing medical tourism development. The designed model incorporates these three important factors that have remained the focal points in the world of medical tourism. Hence, the result reveals empirical evidence suggesting that the finance, system, and the connection factors significantly foster the growth of tourist arrivals in Dubai. Moreover, it predicates that the significant improvement in the economy of Dubai administrative government is likely to be connected with the development of its medical infrastructure. Additionally, by employing the use of SMART PLS (partial least square) software package, the structural analysis tests, like model fit, further affirms the robustness of the results. In addition, the study presents policy implication for the stakeholders in the health sector, tourism sector, and the government.
\end{abstract}

Keywords: medical tourism; finance; system; connections; economic growth; diversification; UAE

\section{Introduction}

Medical tourism is seen as a vacation that entails travelling into foreign countries to access a wide range of health services [1]. Patients who feel that they are spending more than required to access their medical care in their various countries always seek an alternative in other to reduce their medical expenditure [2,3]. Such individuals do this by travelling to other countries where they find it cheaper to obtain the same medical services such as dental, medical, and surgical services than the ones obtained in their home or residence countries. Most patients from both developing and developed countries have had the reason to visit some emerging countries such as the United Arab Emirate (UAE), India, and others to seek medical attention. This is because health services in the aforementioned countries are relatively cheaper, and of better quality than that which is obtained in their countries [3]. In the tourism sectors, health tourism is among the fastest growing section of tourism internationally. The list of countries that are working towards dominating and championing this market legally and practically is fast increasing. This new wave of engagement in the international trade in medical services also has great economic potential for the world economy [4]. Investment in the medical industry is a way to increase the gross domestic product (GDP), improve services, generate foreign exchange, create a more favorable balance of trade, and boost tourism [5]. Health tourism is currently a US $\$ 100$ billion global 
business and this aspect of tourism is currently experiencing an average growth rate of $25 \%$. As such, the stakeholders are continually relying on income from medical tourism because of the perceived growth in medical tourism [6-8].

The business opportunities that are attached to medical tourism have been identified in many countries [9]. The United Nations Economic and Social Commission for Asia and the Pacific (UNESCAP) identified a list of countries that have started experiencing an increase in tourism travelers to their destination in 2005. An estimation of about 2.5 million people was expected to have travelled to the countries-India, Malaysia, Singapore, and Thailand (United Nations Economic and Social Commission for Asia and the Pacific (UNESCAP). Countries such as UAE, India, and the Philippines are leading, emerging major health-care destinations. According to Singh et al. [10], many other countries such as Turkey, Colombia, Argentina, Bolivia, and Brazil are equally on track towards making themselves attractive medical service destinations. Despite the increasing possibilities of this aspect of tourism globally, especially among the emerging economies such as UAE, there is sparse extant literature on the dynamics of medical tourism. Until now, researchers have not really delved into studying this trend, thus only a few academic studies have focused on this sector. Most accessible studies only focus on some aspect of the sector such as economic or marketing aspects of health industry [4,11-13]. Patients have many reasons for visiting overseas for medical attention; the striking ones are the affordability and level of quality of care [14]. Some developing countries such as India and UAE are known for less expensive and high levels of medical care [2]. There is high demand for the expansion of this aspect of tourism and for a more comprehensive theoretical framework to show the new dimensions of this sector.

Generally, in the Arabian region, Egypt became medical tourists' favorite destination in the 1960s. However, the consistent investment in the health sector by the Jordanian government made Jordan overtake Egypt's position in the 1980s. Currently, UAE is not ranked among the first 10 medical tourism destinations in the world. However, the potential for the development of medical tourism which includes the availability of hot water springs, mineral water, and advanced medical technologies among others are available in the region, most of the countries are yet to maximize the opportunities. Having realized this untapped opportunity, the UAE has suddenly become a global hub and a destination favorite of foreign patients seeking high-quality services [15]. Accordingly, the partnership of the government of UAE with prestigious health care companies and organizations like the Cleveland Clinic, John Hopkins University-Al Tawam Hospital partnership, and the Mubadala health care are among the new faces of UAE's health system. In this light, one of the Emirati's main administrative city—Dubai-is fast becoming a major hub for medical tourism. The city's health care is reported to currently staff over 35,000 international professionals from more than 100 countries. Going by this pace, the city's Dubai Health Authority (DHA) is expected to attract over 500,000 medical tourists by 2020 .

Against this backdrop and the motivations, this study aims to develop an integrated new model that will potentially underpin how to trigger greater expansion and harnessing of the potentials of medical tourism. In addition, such a model is expected to retain and maintain the trend of the medical aspect of tourism in the UAE. The study proposes a novel model developed by the authors which is called the FSC (Finance, System, and Connections) Model (Figure 1). The model forms a triangular interaction of the factors. The factors are strong Finance (F), strong System (S), and strong Connections (C). This study includes an in-depth definition of the proposed theory and it is exploratory in nature.

The rest of the sections are arranged as follows. An overview of previous models within the context of medical health care is discussed in Section 2. A brief discussion on the case study-UAE and the research city-Dubai is further discussed in the section. Methodology development, data description and the hypotheses with results are presented in Section 3, while the estimated results were tested using a structural model and model fit in Section 4 . Section 5 offers concluding remarks that include policy implications and recommended prospective studies. 


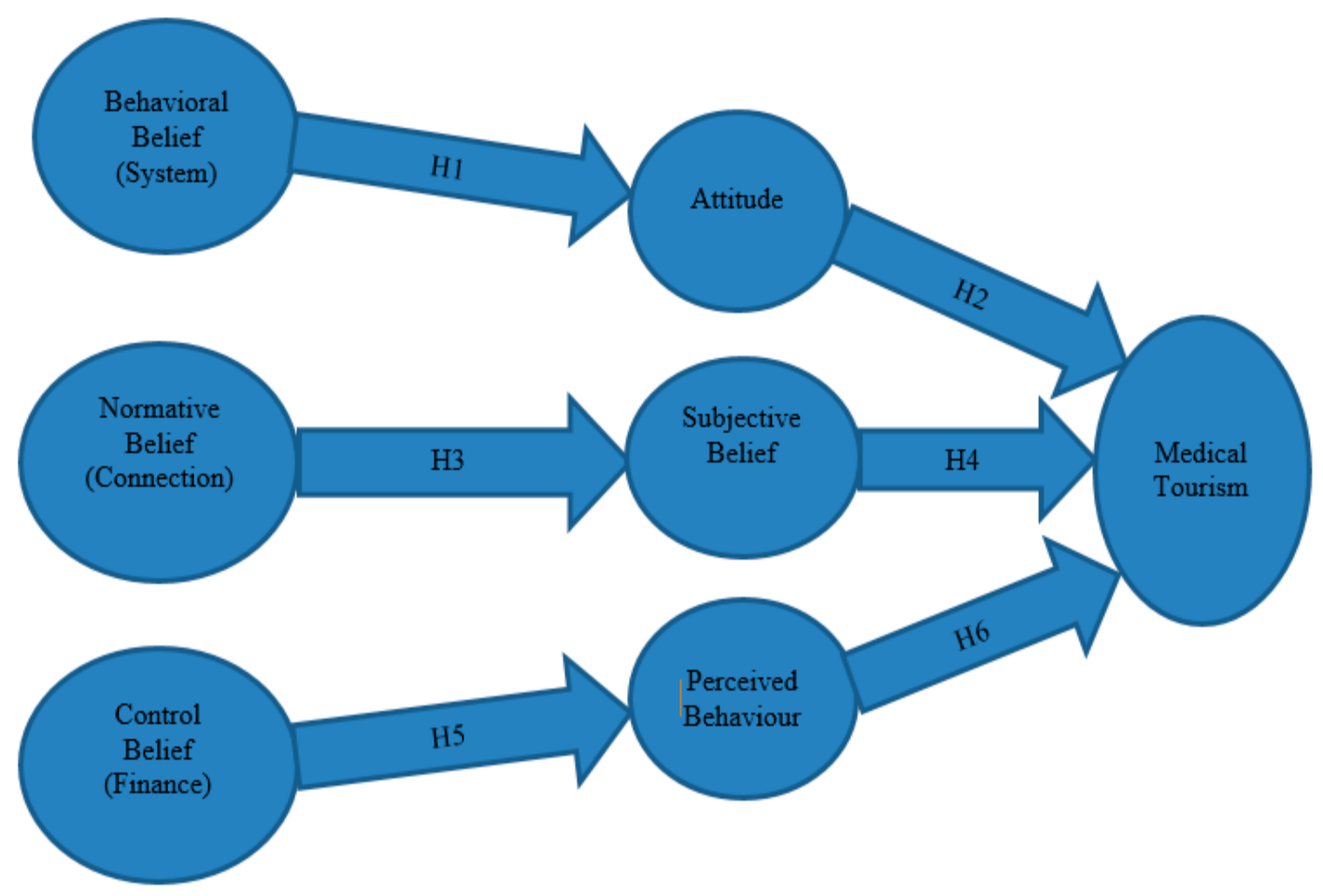

Figure 1. The Proposed Finance, System, and Connection (FSC)/Theory of Planned Behavior (TBP) Research Model.

\section{Literature Review}

\subsection{The Extant Models}

Caballero-Danell and Mugomba [16] developed a model that describes the market structure of health tourism and account for all the stakeholders involved. This action is geared towards providing good and more effective information to aid the understanding of both the current status of medical tourism and the expected development. The model originated from the data gathered from the newspapers, periodicals, electronic media, and magazines and academic materials. It also gives the consumers the access to the analysis and description of the industry as it relates to benefits, branding, legal framework, infrastructure, product, target market, communication channels, operators, intermediaries, and social issues.

Additionally, another existing FSC theory by Smith and Forgione [13] proposes a model that sorts the factors that affect the patient's decision or choice of a medical tourism destination. The model has two stages of depicting the factors. The first stage displays the factors involved in choosing a health care destination, while the second stage depicts the factors involved in choosing a health care facility. There is no dominant factor that determines the destination; rather, all factors are important and equal at the play [13]. The model maintained that country-specific features such as political environment, economic situation, and regulatory policies, determines the choice of destination. However, the costs, quality of care, hospital accreditation and the level of expertise of the physician are known to influence the choice of health care facilities. However, the model presented the two stages of the model, but the selection of destination comes first before the consideration of the health care facilities.

Moreover, Ye Yuen, Qiu and Zhang [17] developed a model that attempt to study the motivations and barriers to medical tourism among the prospective tourists in Hong Kong. They arrived at a conclusion, based on their findings, that the motivations of the medical tourists differ from that of a conventional tourist. While the medical tourists are more interested in the medical factors, the conventional tourists are concerned about the destination features. The research equally found 
some important implications for a health tourism destination. Such findings informed that a marketing program should not focus only on less expensive medical services but highlight other features.

\subsection{Theoretical Context}

The authors developed a conceptual framework on new ways of sustaining the UAE vision 2020 with reference to the existing models on health tourism. They adopted a health-related model of TPB (Theory of Planned Behavior) by Godin and Kok [18] and employed further modification. Hence, three factors (known as the FSC-Finance, strong System, and strong Connections) were employed to display a triangular interaction of the mentioned factors in determining medical tourism.

Finance is a predominant factor in medical tourism [14]. Both from the side of the patients and the industry. The cost of medical service is put into consideration while deciding the medical destination of the patients; most people seek out-of-country care, as in the case of America, because of the cost effect [19]. It is required in deciding the quality of the health care facility both in the areas of medical personnel and the infrastructures and equipment needed for the delivery of efficient health facilities. The quality of health care is always considered as a pointer to a medical destination by patients from high-income countries [20,21]. Hopkins et al. [22], in an attempt to paint the importance of finance, compared the hospitals in the developing world (India) and developed world (America). This involves the pairing of hospitals in India with that of USA hospitals for international accreditation in a bid to woo and attract medical tourists from high-income countries [22]. A documented instance of malpractices and health misadventure, which includes, but not the least, novel infections and post-treatment complications that arise sometime after the patients have returned to their own country [23].

Availability of financial aid is greater, especially, with the integration and commercialization of medical tourism, despite having its own-shortcomings such as brain drain and the lack of quality medical professional in the health care services. This shortcoming further limits the accessibility of medical service for the poor and money-strapped patients [24,25]. The implication of this is that it will be a boost to the medical and tourism industry and the entire economy to having an effective and functional health delivery system as such, that hopes to aid the attainment of the vision 2020. The UAE is among the envisioned high-income countries, but with very low overall health care service spending. Its public system, which covers $81 \%$ of health care finance, provides one bed, 0.33 doctors and one nurse for every 1000 people, which is very insignificant by international standards.

System in our model is the structure and plans on how to establish and run the private health care program that will make the provision of the three important factors that are meant to complement the public health system effectiveness. Medical tourism is best viewed and understood as originating from an increasingly privatized global medical market arising in the awareness of globalization and enhancement of the non-restricted (neoliberal) economic policies. Additionally, this has subsequently led to the expansion of the space of private health care and increase in the market growth of the sector even across the globe [26]. This process is also often called corporate strategy, thus it includes managing medical devices and suppliers, creating clinical standards, transferring skills, branding the name and sharing activities such as vertical integration, mergers, alliances, partnership, and diversification. Apart from corporate strategy, an operating strategy is considered part of the system, which is the formulation of policies, processes, technologies, human resources practices, and organization of work. This also involves people and resources that influence the way the service is perceived by patients and the results achieved on a day-to-day basis. As such, the theory is embedded around the system which is called Hallow Health Tourism System (HHTS). Moreover, the aforementioned design complies with the aim of the UAE in making Dubai a hub of health care that is meant to boost the growth of the medical tourism market. The awareness of this program was put up by the UAE as the first health care free zone with the initiative of embarking on the massive treatment of foreigners [21]. This idea was sold to the international entrepreneurial health care providers such that encourages their operational services across the city. Among the incentives involved, it is $100 \%$ tax-free, there is access to $100 \%$ foreign ownership and no imposition of capital or trade restrictions. On this premise, and by 
utilizing the opportunity provided by the UAE government, the developer of the theory employs a practical by launching the system (HHTS) to coordinate the entire practical activity and not only the theoretical approach.

Connection is considered as the international exposure of the health care providers. In most cases, the capability of the private health care provider is assessed through international exposure via connections with both domestic and international partners on the same line of operation [27]. This is perceived as a design for enhancing the viability of the business through the sponsoring of foreign experts into the place of domicile. The connection factor also arises when the operators are perceived to be well connected to the government officials, thus, such influence is expected to be advantageous for fostering the operations without undue interference from the powers [28]. This sometimes aids the private operators to easily penetrate and collaborate with public-owned health care facilities that will enhance the performance of both parties.

\subsection{The Study Area: United Arab Emirates}

According to the UAE Government Strategy of 2007, the focus areas of the economy are on infrastructure, small- and medium-sized businesses (the commerce), real estate and construction, banking and finance, tourism and hospitality, manufacturing and industrial development, medical, education, and the retail sectors. There are relative economic growth and expansion of business opportunities in the above-mentioned economic areas [19]. The real estate sector received a new deal that attracted foreign investment in March 2006 that is now observed to contribute about $15 \%$ to the non-oil GDP [29].

In view of the diversification pattern of the UAE economy, it is paramount to consider the opportunities that come from importing of good and services. UAE is a net service importer [19]. As such, transportation vehicles, machinery, and electrical equipment accounts for the largest share of the imported goods. Food items are other imported items that are of great value to the economy. According to the report of RNCOS in 2008, UAE imported about $90 \%$ of food items in 2007. Studies reported that UAE was in negotiation with Pakistan and Philippines to buy farms worth US $\$ 5$ billion and to sign a memorandum of understanding (MOU) for food supplies [30,31]. In addition, plastic products are among the products that are far below the demand according to a study released by the Emirates Industrial Bank in 2003. In addition, reports by the UAE interact opined that, as of 2007, a total of US $\$ 3$ billion was invested to expand the capacity of polyethylene and polyolefin of the Borouge's petrochemical facility.

UAE and its economy have been a base for constant research since the inception of the country. The economy has been on the trend of moving from a particular source of revenue to the other starting, thus from oil to presently enlarging its revenues from the tourism industry [9]. According to the UAE interact in 2008, UAE was among the largest oil producing nation and rated 5th worldwide. Unlike most countries with similar resource concentration like the UAE, the UAE economy has drastically moved from a mono-economy and toward rapid diversification. Rather, the dependency of the UAE on oil went down to as low as $40 \%$. According to IMF [32], the UAE has the largest Sovereign Wealth Funds (SWF) as an investment. The global diversified plans and strategies and the capital investments in infrastructural projects of the nation UAE have placed the country in a strategic position in the Middle East region in both the business and tourism [32]. According to the record of Standard Chartered, the global recession of 2008-2009 could barely have had a significant impact on the UAE economy, which is forecasted to have grown by $2.7 \%$ even when the global GDP is expected to grow just by $0.5 \%$ even in the midst of the Global Financial Crisis [33].

Not only that the UAE is a business hub, but the wave of expansion in the tourism industry and now in the medical tourism, in particular, is viewed as a new dimension that taking the lead toward the 2020 sustainable goals. According to Al Deen, Dhabi and Matar [34], the UAE government has been spending over US $\$ 2$ billion every year for its citizens on medical treatment outside the country. Apart from capturing the market, UAE is shifting its attention towards medical tourism that had 
global revenues exceeding US $\$ 56$ billion in 2007. In addition, the medical tourism generated $\mathrm{Dh} 7$ billion yearly to the UAE economy by 2010 in accordance with Abu Dhabi Chamber of commerce and Industry in 2007 [34]. The UAE has strategized and place itself as a force to reference within the health tourism sector by positioning themselves at the 16th most wanted to visit or destination choice of the medical tourists. This is because the government of UAE seems to be very proactive in developing and boosting the Medicare facilities [9]. The report reiterated that the per capita Medicare consumption in the UAE is the second highest in the region. In an effort to attract medical tourists from all over the world, the government came up with a program called Dubai Health Experience (DXH). This program is made up of 25 health care facilities that formed the DXH group. The government has also come up with a friendly, single window smart application and digital gateway for the medical tourists in order to benefit from the superior, comprehensive integrated Medicare service system. This program will aid patients with a booking platform for procedures, visas, discounted Emirates flight tickets, hotels, sightseeing, and insurance. The UAE will definitely meet its target of becoming the fifth medical tourist destination by 2020 if the government continues with this progressive dimension [35].

In the Country Brand Index of 2008, UAE has been on the top list of performance both in tourism and on other sectors of the economy. In resorts and holidays options, it is rated as number one in the brand ranking. For new businesses and shopping destinations, UAE became number two in the brand, number seven for conferences, and number 10 for advanced technology and standard of living with fine dining. As further declared by Raza Siddiqui, the executive director of Ras Al Khaimah (RAK) [36], UAE has tremendous potential to emerge as the next important tourism destination in the region.

\section{Dubai}

In UAE, Dubai has no competitor in terms of the most populated city in the United Arab Emirates (UAE). It is positioned and located on the southern coast of the Persian Gulf within the Arabian Peninsula [37]. Dubai is currently gaining momentum in the health care service and in the medical tourism destination [38]. This significant growth is due to the low cost in accessing medical service in the city, good English language proficiency level of staff, and the faster rate of receiving medical treatments. The Dubai administrative government places more values to health care as a means of economic growth, given its limited oil reserves, and its drive toward the target of attaining a global center for high-level services [39]. It is not a surprise that Dubai recently became a potential hub for medical travel, due to its high-handedness of managing the economy by the government and the direction from the government [40]. In the speech accredited to the Vice and Prime Minister of UAE and the ruler of Dubai while appreciating the flagging off of a medical travel project, he commands the integrated process of development and likened it to a bridge between Europe and Asia. Moreover, Dubai city is recommended as a destination for medical tourism by the award from the international medical travel journal (IMTJ) [41].

\subsection{Hypothesis Development}

The focal planned behavior is the intention (i.e., traveling for health tourism) and this is what is described as the person's planned future behavior [42]. In this work, medical tourism is expected to provide a better predictor of the behavior, as in the place of intention, as previously expressed by Fishbein and Ajzen [43]. The FSC/TPB model construct puts the individual's intention to perform a specific behavior, such as travelling for health tourism, as being determined by the attitude and subjective norm. The attitude and subjective norms include both behavior and perceived behavioral control. The health-related work by Godin and Kok [18] with the application of TPB model yielded an average R-square of 0.34 . The FSC/TPB considers the attitude (AT), subjective norm (SN) and perceived behavioral control (PBC) as among the independent factors that determine the intention (traveling for medical tourism) and behavior. AT is the individual reaction of being in support or against the intention or a certain behavior [44]. AT measures the Behavioral Belief System [45]. Behavioral Belief evolves the attitude towards undergoing a task for the sake of overcoming (whether successful or 
not) [46-48]. Concerning health tourism, if prospective tourists plan to visit Dubai for health care and the outcome of the medical care is anticipated to be satisfactory, they will expectedly embark on health tourism to Dubai again. In this circumstance, the projection for health tourism would expectedly increase.

The subjective norm measures the opinions of others who are either close or important to someone, and as such influence his/her decision making [48]. This also translates that the intentions of the prospective tourists to Dubai for health care or treatment might be influenced by the opinions of others who are either close or important them. Subjective norm characterizes a prospective tourist's normative beliefs that inform the decision of people on what to do [46]. In the current study, and generally in health tourism, if the close relatives of a prospective tourist want him or her to embark on medical travel to Dubai, his or her intentions to go for the treatment will be high and vice versa. Hence, it is expected that subjective norm influences the intentions of the prospective medical tourists to travel to Dubai for health care or treatment.

Perceived Behavioral Control (PBC) is associated with someone's perception of how easy or difficult it is to perform a specific behavior [45]. The perceived behavioral control comprises of the control beliefs (CBs). The control belief (CBs/Finance) is the major factor that measures the perception of the prospective tourists' resources availability (which is measured with finance) that is required to execute a specific behavior [48,49]. In respect to the current study within the context of health tourism, the perceived control belief means to know how one can gain access to Dubai, and whether one can afford the medical treatment based on external resources constraints. It, however, suggests that even if a prospective tourist has done well with the other mentioned factors but is lacking on finance to pay for the travel to Dubai and all the expenses of the health medication, the intention of such tourist will be lower. In other words, a prospective health tourist with high intention to visit Dubai for health care will be motivated because of the availability of an inexpensive but good medical standard of Dubai's medical system through the introduction of HHTS.

Hypothesis 1 (H1). BB (SYSTEM) is not a positive predictor of AT for a prospective health tourist's decision-making process to travel to Dubai for Health Treatment (HT).

Hypothesis 2 (H2). AT is not a positive determinant of intention to travel to Dubai for Health Tourism (HT).

Hypothesis 3 (H3). Normative Belief/Connection (NB) are not positive determinants of subjective norm (SN) for the prospective tourist's decision-making process to travel to Dubai for Health Treatment.

Hypothesis 4 (H4). Subjective Norm (SN) is not a positive determinant of intention to travel to Dubai for Health Treatment (HT).

Hypothesis 5 (H5). Control Belief/Finance (CBS) is not a positive predictor of $P B C$ for the prospective tourist's decision making process to travel to Dubai for Health Treatment (HT) [45].

Hypothesis 6 (H6). Perceived Behavioral control (PBC) not is a positive determinant of the motivation behind the prospective tourist's intention to travel to Dubai for Health Treatment (HT).

\section{Research Methodology}

In this study, we employed a quantitative experimental approach such that data were collected by using a questionnaire as the statistical instrument. The data was collected online with respondents asked about the quality of services available at medical centers, especially in Dubai. Dubai was chosen for the study, as it is the one of the most popular medical tourism destination hub because of high investment in state of the art medical equipment. The first respondent submitted the online-completed 
form at 11:52:29 (UAE time) on 7 June 2018 while last returned questionnaire was received at 18:02:52 (UAE time) on 13 June 2018.

The measures in the questionnaire were constructed by adopting from existing valid and reliable sources [42-51]. The 320 total questionnaires were distributed among the participants and 303 of the questionnaire copies were considered as completed and reliable. Therefore, the response rate was $94.70 \%$. Translation of the questionnaire was not necessary because the questions were written and administered in English. Prior to the collection of the data, a pilot study was conducted with 25 participants at random in order to verify the quality of the questionnaire. We applied the SMART PLS (partial least square) software package in conducting the structural equation analysis. The objective was to throw more light on model fit and variance of the model construct via the path coefficient analyses. This system is based on an iterative combination of the major component analyses and regression. The advantage of utilizing the PLS technique is its ability to simultaneously incorporate both the path coefficients and other estimates without any bias and inconsistent parameter from the side of the researcher $[15,52]$. This model is prediction oriented which makes it a good parameter for prediction.

\section{Findings}

The descriptive statistics in Table 1 shows both the mean and the standard deviations of the variables in question. The variable with the highest mean is the system with 40.43 followed by the finance with 25.69 and the connection with 13.25.

Table 1. Descriptive statistics.

\begin{tabular}{cccc}
\hline Variables & Observations & Mean & Standard Deviation \\
\hline Medical Tourism & 303 & 17.4488 & 3.3969 \\
System & 303 & 40.4323 & 7.2674 \\
Finance & 303 & 25.6864 & 5.4247 \\
Connection & 303 & 13.2475 & 2.5072 \\
\hline
\end{tabular}

The correlation test results at Table 2 depicts positive and statistically significant relations with moderate relationship existing among the examined variables. In addition, there is empirical evidence of lesser concern for the presence of the multi-collinearity problem. The assumption here is that the closer the relationship that exists between the variables the greater the multi-collinearity. In addition, from the result of the test, it is observed that the highest number that is up to the average of one is 0.5858 .

Table 2. Correlation matrix.

\begin{tabular}{ccccccc}
\hline Construct & Medical Tourism & System & Finance & Connection & Prob & Observations \\
\hline Medical Tourism & 1.0000 & 0.4611 & 0.5406 & 0.4868 & 0.00 & 303 \\
System & 0.4611 & 1.0000 & 0.5858 & 0.5563 & 0.00 & 303 \\
Finance & 0.5406 & 0.5858 & 1.0000 & 0.5790 & 0.00 & 303 \\
Connection & 0.3299 & 0.5563 & 0.5790 & 1.0000 & 0.00 & 303 \\
\hline
\end{tabular}

\subsection{Hypotheses Tests}

Following the establishment of the above hypotheses, a linear regression of quantitative analysis was employed to estimate the associated empirical evidence. The estimation observes that (see Table 3) the R-square is $35 \%$ which means that $35 \%$ of the relationship between the dependent (Medical Tourism) and the independent variables (FSC) can be explained. Although the result of the Durbin Watson (1.7) is close to 2, there is empirical evidence of no serial correlation or autocorrelation. 
Table 3. Model summary.

\begin{tabular}{ccccccc}
\hline Model & R & R Square & Adjusted R Square & Std. Error of the Estimate & Sig. F Change & Durbin-Watson \\
\hline 1 & 0.592 & 0.350 & 0.344 & 2.750 & 0.000 & 1.7 \\
\hline
\end{tabular}

Moreover, the estimates further show that the three factors (FSC) are all positively related with Medical Tourism as indicated in Table 4. Except for the relationship between System and Medical Tourism, which is statistically significant at the $5 \%$ significance level, the associations of Finance and Connection with Medical Tourism are significant at the $1 \%$ significance level. In addition, the impacts of Finance and Connection on Medical Tourism are very similar (0.2065 and 0.2881 respectively), while the System impact on Medical Tourism is lower (0.0699).

Table 4. Linear regression.

\begin{tabular}{ccccc}
\hline Independent Variable & Coefficient & Standard Error & $\boldsymbol{t}$-Stat & $\boldsymbol{p}$-Value \\
\hline (Constant) & 5.499 & 0.9971 & 5.5147 & $0.000^{* * *}$ \\
System & 0.0699 & 0.0284 & 2.4577 & $0.015^{* * *}$ \\
Finance & 0.2065 & 0.0388 & 5.3159 & $0.000^{* * *}$ \\
Connection & 0.2881 & 0.0819 & 3.5141 & $0.001^{* * *}$ \\
\hline
\end{tabular}

Dependent Variable (Medical Tourism) ${ }^{* * *}(p<0.01)$.

Similarly, the H1: BB (SYSTEM) is not a positive predictor of AT for a prospective health tourist's decision-making process to travel to Dubai for Health Treatment (HT). In addition, H2: AT (Attitude) not is a positive determinant of intention to travel to Dubai for Health Tourism (HT). The outcome of the linear regression (see Table 4) shows that the null hypothesis is rejected given that the coefficient and the $t$-statistics are respectively 0.0699 and 2.4577 . Hence, the alternative hypotheses for the two hypotheses above are accepted. The results translate that System is statistically significant and with a positive relationship with Medical Tourism. This is in line with the study expectation and an indicator that better achievement of medical tourism in UAE can be sustainable with the System strategy. This means that there is a need to maintain an attractive and conducive system in the industry. Again, the H3: Normative Belief/Connection (NB) is not a positive determinant of subjective norm (SN) for the prospective tourist's decision-making process to travel to Dubai for Health Treatment. Additionally, the H4: Subjective Norm (SN) is not a positive determinant of intention to travel to Dubai for Health Treatment (HT). Given the $t$-statistic of 3.5141, which is statistically significant at $1 \%$, the above null hypotheses of $\mathrm{H} 3$ and $\mathrm{H} 4$ are rejected. Therefore, the study accepts the alternative hypotheses. The result shows a positive coefficient of 0.2881 and is statistically significant at the $p$-value (0.010). This supports the hypothesis that Connection positively affects or determines the choice of a medical tourist in choosing a medical tourism destination. Lastly, the H5: Control Belief/Finance (CBS) is not a positive predictor of PBC for the prospective tourist's decision-making process to travel to Dubai for Health Treatment (HT). Additionally, H6: Perceived Behavioral control (PBC) is not a positive determinant of the motivation behind the prospective tourist's intention to travel to Dubai for Health Treatment (HT). Likewise, the null hypotheses H5 and H6 can be rejected based on the result of the linear regression (see Table 4) that showed that Finance determines the choice of a medical tourist in regards to the choice of the tourism destination. The result shows that Finance has a positive relationship with medical tourism given that the coefficient and $t$-statistics are respectively 0.2065 and 5.3159 with the $p$-value of 0.000 .

\subsection{Structural Model}

In addition to the above regression analysis, we expanded our research by adding some structural analysis such as;

(i) Alpha reliability 
(ii) Estimated composite reliability

(iii) Average Variance Extracted

(iv) Model Fit and $\mathrm{R}^{2}$

(v) Estimated path coefficients estimations and its bootstrap confidence intervals.

The three figures below display the results of the structural model, and all were done in consistency PLS Bootstrapping. The arrows included in the model show the path coefficients for only path coefficient, path coefficient with $t$-values, and path coefficient with $p$-values that are listed in the path coefficient as estimates. We adopted the 1000 sub by default to estimate the path coefficient, $t$-test, and $p$-values to determine and decide whether each causal order was significant. All the path coefficients were found to be significant at the 0.001 level with the expected signs and direction. In addition, all the $t$-values are above 1.96 which is the $5 \%$ significant level. It then shows that all the coefficients are statistically significant. Furthermore, the $p$-values are all significant, even at 0.001 (1\% significant level).

\subsubsection{Proposed Measurement Scales with Smart PLS}

Table 5 below represents the alpha coefficients for the items within each construct and this shows that all of them are above 0.70 , which is the threshold. In this case, the minimum is 0.662 which is the exact threshold if approximated to 070 . The composite reliability also conforms to the values obtained from the alpha that shows that it avoided the assumption of equal weighting of the items. The average variance extraction seems to be before the threshold of 0.5 , but this could be attributed the nature of the Average Variance Extracted (AVE) that most times seems to be the tougher analyses of the reliability. With the Alpha and the composite reliability values, the reliability of the model is robust.

Table 5. Construct reliability and validity.

\begin{tabular}{ccccc}
\hline & Cronbach's Alpha & rho_A & Composite Reliability & Average Variance Extracted (AVE) \\
\hline Connection & 0.662 & 0.687 & 0.673 & 0.344 \\
Finance & 0.864 & 0.867 & 0.864 & 0.444 \\
Medical Tourism & 0.807 & 0.812 & 0.807 & 0.458 \\
System & 0.890 & 0.892 & 0.889 & 0.402 \\
\hline
\end{tabular}

\subsubsection{Model Fit}

Table 6 below displayed a model fit with the overall fit at 74.5. The model fit is good at the overall goodness of fit (GFI) which falls into the index according to Tenenhaus et al. [53] (GFI = 0.77). The quality of the model is good and falls into the proposed overall fit. Our model shows a good and high level of forecasting power with $74.5 \%$ of the variance in satisfaction. The model has a good fit and is a good model.

Table 6. Model fit summary.

\begin{tabular}{ccc}
\hline & Saturated Model & Estimated Model \\
\hline SRMR & 0.061 & 0.106 \\
d_ULS & 1.606 & 4.920 \\
d_G1 & 0.583 & 0.719 \\
d_G2 & 0.542 & 0.633 \\
Chi-Square & 921.28 & 1044.49 \\
NFI & 0.775 & 0.745 \\
\hline
\end{tabular}

\subsubsection{The Models}

From the model structure below, the path coefficients of the variables are highly significant with the $t$-values on the path coefficient arrows (Figure 2). The $t$-statistics of all the coefficients of the 
variables are highly significant because they are above the threshold of 1.96; this is a great pointer that the model is free from the collinearity problem.

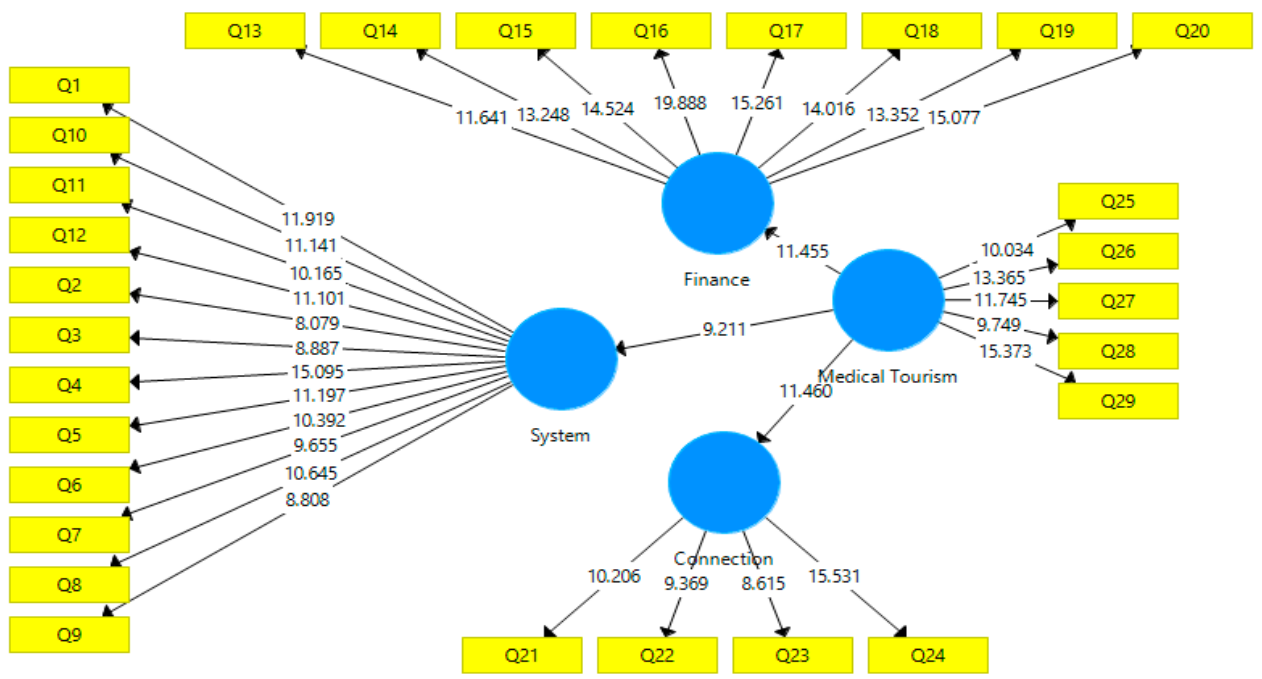

Figure 2. Model with $t$-value of the coefficient.

From the model structure below (Figure 3), the entire path coefficients are significant with the values above or equal to 0.5 at 0.001 . All the path coefficients were found to be significant at the 0.001 level with the anticipated signs and direction that show a good structural model fit. This shows that there is an interaction or causality passing through the variables to the targeted variable, Medical Tourism.

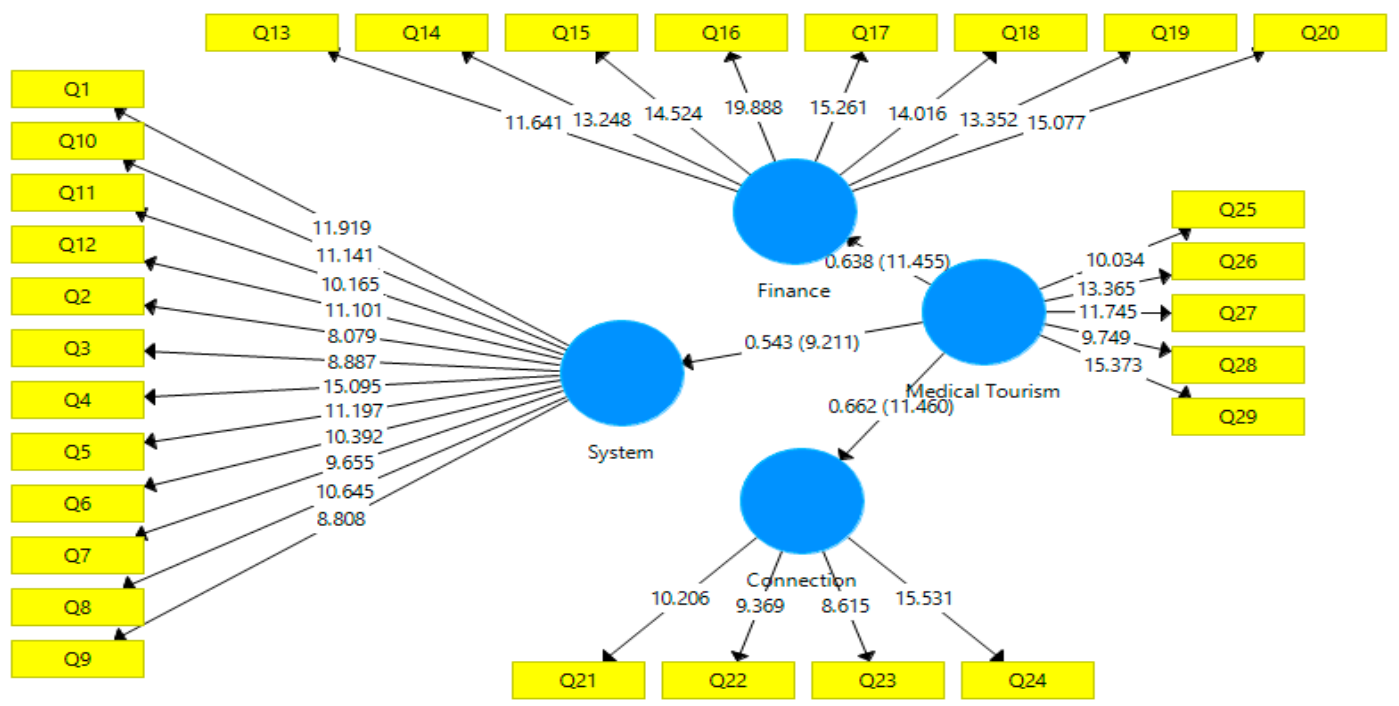

Figure 3. Model with path coefficient and $t$-values.

In addition, the path coefficients with $p$-values are all well measured (Figure 4) with the expected signs and level of significant at 0.001 . The $p$-values are statistically significant, even at $1 \%$. 


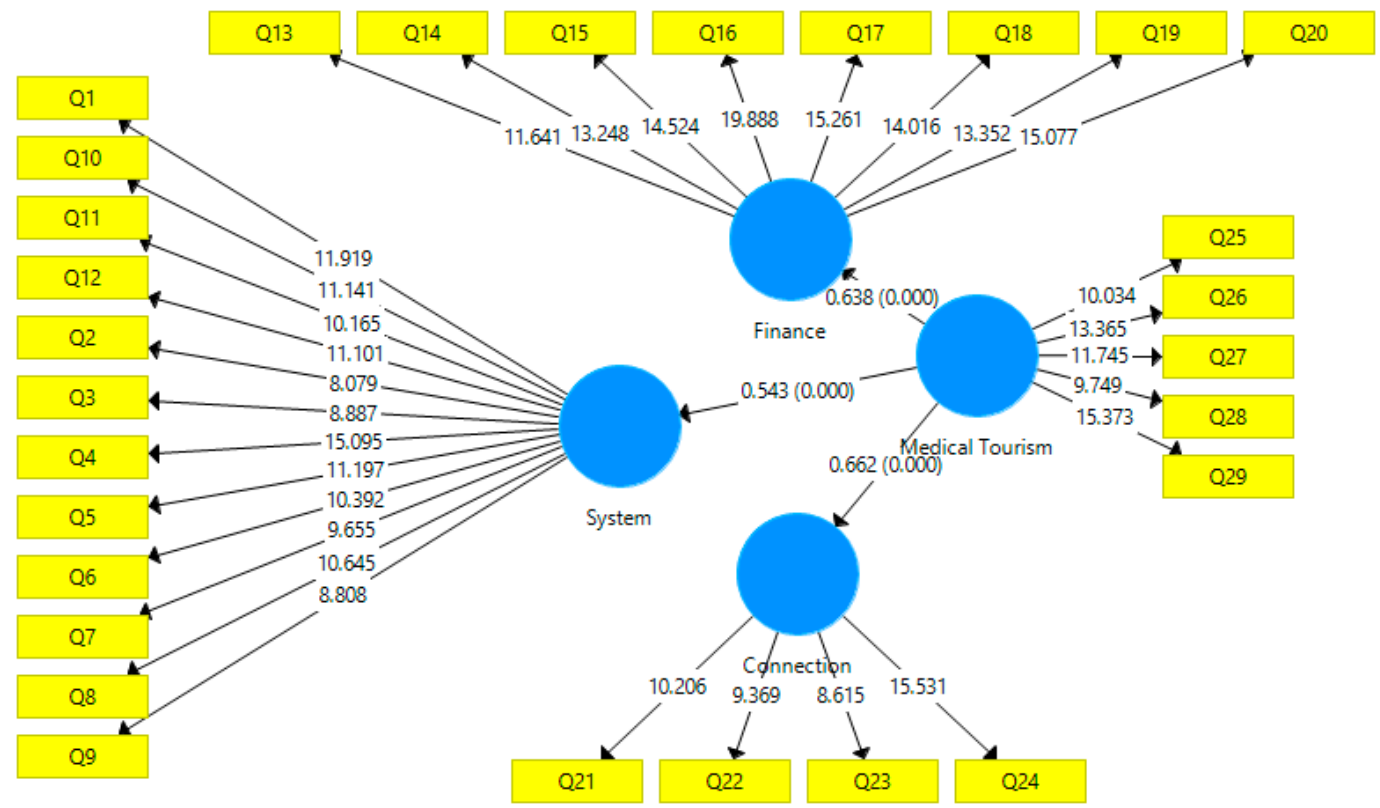

Figure 4. Model with path coefficient and $p$-values.

In Table 7 , the $p$-value for each estimated path shows that all path coefficients are significant. In addition, the $t$-statistics of all the coefficients of the variables are statistically significant since they are all above the threshold of 1.96. Hence, it is a good indicator that the model is free from the collinearity problem and the estimated coefficients have the same sign that shows that the variables are normally distributed. Additionally, the analysis of R-square coefficients explained the robustness of the finance and connection, thus, the model and its antecedents explain over $30 \%$ of the system construct. Other endogenous constructs also displayed the value of the R-square coefficients.

Table 7. Estimated path coefficient estimations and its bootstrap and confidence interval.

\begin{tabular}{cccccc}
\hline From & To & Estimate & $\mathbf{R}^{\mathbf{2}}$ & $\boldsymbol{t}$-Value & $\boldsymbol{p}$-Value \\
\hline Medical Tourism & Finance & 0.638 & $40.8 \%$ & 11.455 & 0.000 \\
Medical Tourism & Connection & 0.662 & $43.9 \%$ & 11.460 & 0.000 \\
Medical Tourism & System & 0.543 & $30 \%$ & 9.211 & 0.000 \\
\hline
\end{tabular}

\section{Concluding Remarks and Policy Implications}

The bedrock of every business is an idea. This idea will definitely not go any longer without the applicability of the three factors studied in our model: Finance, system, and connection. Even from the statistical analyses in this work, it is observed that the chosen factors have a positive relationship with the medical tourism and they are statistically significant in determining the choice of the medical tourist and their tourism destinations. Dubai is considered among the emerging cities with good infrastructures like airlines, hospitals, good roads and hotels, and open for a market in all sectors of the economy, which tourism as a whole and medical tourism in particular, is among them. These three factors characterize the opening up of Dubai to the rest of the world. As such, the study suggests that Dubai possesses the potential to increase the traffic of tourists to come to Dubai, especially for the purpose of health. With the UAE's desire to meet the country's vision 2020 and subsequently turning Dubai into a medical tourist destination, evidence suggests that such vision is not far from reach. Hence, the UAE's medical tourism policy is effectively driving the policy vehicle to meeting the Sustainable Development Goal 2030, especially, through sustainable good health and well-being. 


\section{Policy Implications}

The findings of the current research present useful policy implications and direction for the stakeholders in the industry. Due to the significance of the FSC, it then suffices an implication for the government to implement policies effectively that are observed to lubricate further directly, or indirectly, the examined factors (FSC). For instance, in the aspect of finance, both the government of $\mathrm{UAE}$ and the administrative government of Dubai are expected to create an enabling environment for private investors. The implementation of such policy direction is billed to yield the success report enumerated by the Gulfnews (2018) [54]. Since the industry is liberalized, the government policies like the tax reduction policy on importation of medical equipment will go a long way at aiding the performance of the privately-owned health outfit. Hence, it suggests that if the above tested factors are efficiently implemented in the business of Medical Tourism in UAE, it will tangibly contribute to the achievement of making these targets of UAE a reality. However, there are some limitations for this study. The main limitation of this study is that there are good medical tourism destinations, such as Turkey, in the region that are well known in the industry [2]. Another limitation of this study is that the government of UAE should provide proper strategies in order to involve the private sectors to invest in medical tourism. The future research recommendations of this study are that Dubai should design and implement proper strategies, which encourage the local and foreign investors to participate in medical tourism in a way that enables Dubai to compete with the other competitors such as Turkey in the region. Lastly, there are usually two factors that need to be resolved to improve the medical tourism in Dubai, such as the high cost of medical treatment in Dubai and the lack of having elite doctors residing in Dubai. The above-mentioned factors need to be sorted out in a way to build a brand image for Dubai in medical tourism. This is because proper collaboration is required among the policymakers and the travel and tourism sectors of the Dubai [55].

Author Contributions: H.A.-T. contributed to visioning, conception and design of study, collection of data, data analysis and interpretation, drafting the article. H.K. contributed to revising the manuscript critically, drafting the article, and general supervision. A.O. contributed to the writing of the manuscript, critical revision of the article, implementing the corrections, and general supervision. S.O.Q. contributed to the design and implementation of the research, to the analysis of the results and to the writing of the manuscript.

Funding: This research received no external funding.

Conflicts of Interest: The authors declare no conflicts of interest.

\section{References}

1. Connell, J. Contemporary medical tourism: Conceptualisation, culture and commodification. Tour. Manag. 2013, 34, 1-13. [CrossRef]

2. Momeni, K.; Janati, A.; Imani, A.; Khodayari-Zarnaq, R. Barriers to the development of medical tourism in East Azerbaijan province, Iran: A qualitative study. Tour. Manag. 2018, 69, 307-316. [CrossRef]

3. Goodrich, J.N.; Goodrich, G.E. Health-care tourism-An exploratory study. Tour. Manag. 1987, 8, 217-222. [CrossRef]

4. Bookman, M. Medical Tourism in Developing Countries; Springer: Berlin, Germany, 2007.

5. Skountridaki, L. Barriers to business relations between medical tourism facilitators and medical professionals. Tour. Manag. 2017, 59, 254-266. [CrossRef]

6. Suess, C.; Baloglu, S.; Busser, J.A. Perceived impacts of medical tourism development on community wellbeing. Tour. Manag. 2018, 69, 232-245. [CrossRef]

7. Pilkington, M. Can Blockchain Technology Help Promote New Tourism Destinations? The Example of Medical Tourism in Moldova. SSRN Electron. J. 2017. [CrossRef]

8. MacReady, N. Developing countries court medical tourists. Lancet 2007, 369, 1849-1850. [CrossRef]

9. Inhorn, M.C. Medical Cosmopolitanism in Global Dubai: A Twenty-first-century Transnational Intracytoplasmic Sperm Injection (ICSI) Depot. Med. Anthropol. Q. 2017, 31, 5-22. [CrossRef]

10. Singh, A.S.; Mulder, C.; Twisk, J.W.; Van Mechelen, W.; Chinapaw, M.J. Tracking of childhood overweight into adulthood: A systematic review of the literature. Obes. Rev. 2008, 9, 474-488. [CrossRef] 
11. Lovelock, B.; Lovelock, K. "We had a ball ... as long as you kept taking your painkillers" just how much tourism is there in medical tourism? Experiences of the patient tourist. Tour. Manag. 2018, 69, 145-154. [CrossRef]

12. Connell, J. Medical tourism: Sea, sun, sand and ... surgery. Tour. Manag. 2006, 27, 1093-1100. [CrossRef]

13. Smith, P.C.; Forgione, D.A. Global outsourcing of health care: A medical tourism decision model. J. Inf. Technol. Case Appl. Res. 2007, 9, 19-30.

14. Ganguli, S.; Ebrahim, A.H. A qualitative analysis of Singapore's medical tourism competitiveness. Tour. Manag. Perspect. 2017, 21, 74-84. [CrossRef]

15. Kumar, D.S.; Purani, K. Model specification issues in PLS-SEM: Illustrating linear and non-linear models in hospitality services context. J. Hosp. Tour. Technol. 2018, 9, 338-353. [CrossRef]

16. Caballero-Danell, S.; Mugomba, C. Medical Tourism and Its Entrepreneurial Opportunities: A Conceptual Framework for Entry into the Industry. Master's Thesis, Graduate Business School, Ballarat, Australia, 2007.

17. Ye, B.H.; Yuen, P.P.; Qiu, H.Z.; Zhang, V.H. Motivation of medical tourists: An exploratory case study of Hong Kong medical tourists. In Proceedings of the Asia Pacific Tourism Association (APTA) Annual Conference, Bangkok, Thailand, 9-12 July 2008.

18. Godin, G.; Kok, G. The theory of planned behavior: A review of its applications to health-related behaviors. Am. J. Health Promot. 1996, 11, 87-98. [CrossRef] [PubMed]

19. Alsharif, M.J.; Labonté, R.; Lu, Z. Patients beyond borders: A study of medical tourists in four countries. Glob. Soc. Policy 2010, 10, 315-335. [CrossRef]

20. Trachtman, J.P. The Constitutions of the WTO. Eur. J. Int. Law 2006, 17, 623-646. [CrossRef]

21. Muhajarine, N.; Vu, L.; Labonte, R. Social contexts and children's health outcomes: Researching across the boundaries. Crit. Public Health 2006, 16, 205-218. [CrossRef]

22. Hopkins, L.; Labonté, R.; Runnels, V.; Packer, C. Medical tourism today: What is the state of existing knowledge? J. Public Health Policy 2010, 31, 185-198. [CrossRef]

23. Newman, A.B.; Foster, G.; Givelber, R.; Nieto, F.J.; Redline, S.; Young, T. Progression and regression of sleep-disordered breathing with changes in weight: The Sleep Heart Health Study. Arch. Intern. Med. 2005, 165, 2408-2413. [CrossRef]

24. Tang, C.F.; Lau, E. Modelling the demand for inbound medical tourism: The case of M alaysia. Int. J. Tour. Res. 2017, 19, 584-593. [CrossRef]

25. Turner, L. Medical tourism: Family medicine and international health-related travel. Can. Fam. Phys. 2007, 53, 1639-1641. [PubMed]

26. Labonté, R.; Schrecker, T.; Packer, C.; Runnels, V. (Eds.) Globalization and Health: Pathways, Evidence and Policy; Routledge: Abingdon, UK, 2009.

27. Bozinoff, N.; Dorman, K.P.; Kerr, D.; Roebbelen, E.; Rogers, E.; Hunter, A.; Kraeker, C. Toward reciprocity: Host supervisor perspectives on international medical electives. Med. Educ. 2014, 48, 397-404. [CrossRef] [PubMed]

28. Beladi, H.; Chao, C.C.; Ee, M.S.; Hollas, D. Does Medical Tourism Promote Economic Growth? A Cross-Country Analysis. J. Travel Res. 2017. [CrossRef]

29. Esiyok, B.; Çakar, M.; Kurtulmuşoğlu, F.B. The effect of cultural distance on medical tourism. J. Destin. Mark. Manag. 2017, 6, 66-75. [CrossRef]

30. Roberts, A.; Rogerson, R. Chinese approach on regulating food additives, novel foods, functional foods and dietary supplements. In Nutraceutical and Functional Food Regulations in the United States and around the World; Elsevier: New York, NY, USA, 2008; pp. 291-303.

31. Maceda, C. UAE signs MoU with Philippines to ensure food supply. Gulf News, 22 July 2008.

32. Balakrishnan, M.S. Approaches to enter emerging markets: A UAE case study. In Proceedings of the 9th Annual Hawaii International Conference on Business, HI, USA, 12-15 June 2009; pp. 1-28.

33. Bundhun, R. UAE monthly household income revealed. Culture \& Society-News, 3 February 2009.

34. Al Deen, M.E.; Dhabi, A.; Matar, R.K. Medical tourism in UAE to generate Dh7b by 2010. Gulf News, 29 April 2007; p. 38.

35. Assembly, N.P. Hybrid Warfare: NATO's New Strategic Challenge? DSC 2015; NATO Parliamentary Assembly: Brussels, Belgium, 2015.

36. Paterson, A.H.; Bowers, J.E.; Bruggmann, R.; Dubchak, I.; Grimwood, J.; Gundlach, H.; Schmutz, J. The Sorghum bicolor genome and the diversification of grasses. Nature 2009, 457, 551. [CrossRef] [PubMed] 
37. Mainil, T.; Van Loon, F.; Dinnie, K.; Botterill, D.; Platenkamp, V.; Meulemans, H. Transnational health care: From a global terminology towards transnational health region development. Health Policy 2012, 108, 37-44. [CrossRef]

38. Ganji, S.H.; Kashyap, M.L.; Kamanna, V.S. Niacin inhibits fat accumulation, oxidative stress, and inflammatory cytokine IL-8 in cultured hepatocytes: Impact on non-alcoholic fatty liver disease. Metab. Clin. Exp. 2015, 64, 982-990. [CrossRef]

39. Rashid, A.M.; Albert, I.; Cosley, D.; Lam, S.K.; McNee, S.M.; Konstan, J.A.; Riedl, J. Getting to know you: Learning new user preferences in recommender systems. In Proceedings of the 7th International Conference on Intelligent User Interfaces, San Francisco, CA, USA, 13-16 January 2002; pp. 127-134.

40. Abu-ElEnain, E.; Yahia, S. Developing medical tourism in Egypt, benchmarking on Dubai, UAE. Int. J. Sci. Res. Technol. 2016, 3, 15-22.

41. Lawrence, D.M. Private Exercise of Governmental Power. Indiana Law J. 1985, 61, 647.

42. Swan, J.E.; Mercer, A.A. Consumer satisfaction as a function of equity and disconfirmation. In Conceptual and Empirical Contributions to Consumer Satisfaction and Complaining Behaviour; School of Business, Indiana University: Bloomington, IN, USA, 1981; pp. 2-8.

43. Fishbein, M.; Ajzen, I. Belief, Attitude, Intention and Behavior: An Introduction to Theory and Research; Addison-Wesley: Reading, MA, USA, 1975.

44. Ajzen, I.; Fishbein, M. Understanding Attitudes and Predicting Social Behavior; Prentice Hall: Upper Saddle River, NJ, USA, 1980.

45. Ajzen, I. The theory of planned behavior. Organ. Behav. Hum. Decis. Process. 1991, 50, 179-211. [CrossRef]

46. Cheng, S.; Lam, T.; Hsu, C.H. Negative word-of-mouth communication intention: An application of the theory of planned behavior. J. Hosp. Tour. Res. 2006, 30, 95-116. [CrossRef]

47. Han, H.; Hsu, L.T.J.; Lee, J.S. Empirical investigation of the roles of attitudes toward green behaviors, overall image, gender, and age in hotel customers' eco-friendly decision-making process. Int. J. Hosp. Manag. 2009, 28, 519-528. [CrossRef]

48. Ajzen, I.; Madden, T.J. Prediction of goal-directed behavior-attitudes, intentions, and perceived behavioral-control. J. Exp. Soc. Psychol. 1986, 22, 453-474. [CrossRef]

49. Francis, J.; Eccles, M.P.; Johnston, M.; Walker, A.E.; Grimshaw, J.M.; Foy, R.; Kaner, E.F.S.; Smith, L.; Bonetti, D. Constructing Questionnaires Based on the Theory of Planned Behaviour: A Manual for Health Services Researchers; Centre for Health Services Research, University of Newcastle upon Tyne: Newcastle upon Tyne, UK, 2004.

50. Janz, N.K.; Becker, M.H. The Health Belief Model: A Decade Later. Health Educ. Q. 1984, 11, 1-47. [CrossRef] [PubMed]

51. Han, H. The health care hotel: Distinctive attributes for international medical travelers. Tour. Manag. 2013, 36, 257-268. [CrossRef]

52. Hooi, T.K.; Abu, N.H.B.; Rahim, M.K.I.A. Relationship of Big Data Analytics Capability and Product Innovation Performance using SmartPLS 3.2. 6: Hierarchical Component Modelling in PLS-SEM. Int. J. Supply Chain Manag. 2018, 7, 51.

53. Tenenhaus, M.; Vinzi, V.E.; Chatelin, Y.M.; Lauro, C. PLS path modeling. Comput. Stat. Data Anal. 2005, 48, 159-205. [CrossRef]

54. Gulfnews. How UAE Became a Medical Tourism Hub. 2018. Available online: https://gulfnews.com/ opinion/op-eds/how-uae-became-a-medical-tourism-hub-1.2239792 (accessed on 19 December 2018).

55. Moghavvemi, S.; Ormond, M.; Musa, G.; Isa, C.R.M.; Thirumoorthi, T.; Mustapha, M.Z.B.; Chandy, J.J.C. Connecting with prospective medical tourists online: A cross-sectional analysis of private hospital websites promoting medical tourism in India, Malaysia and Thailand. Tour. Manag. 2017, 58, 154-163. [CrossRef]

(C) 2019 by the authors. Licensee MDPI, Basel, Switzerland. This article is an open access article distributed under the terms and conditions of the Creative Commons Attribution (CC BY) license (http:/ / creativecommons.org/licenses/by/4.0/). 